\title{
Where should we train doctors in the future?
}

\author{
Less in hospitals, more in general practices
}

From the early nineteenth century until the late twentieth century it has seemed natural, indeed obvious, that medical students should receive their clinical education in teaching hospitals where medical skill and patients with serious illness were concentrated. This system is now under educational and financial threat. Professional and demographic changes and the action of market forces require a review of the fundamental assumptions of basic medical education.

Educationally, the threats can be divided into those that are already with us and those that are as yet only grim prospects. Dwindling local populations combined with the concentration of tertiary care facilities in teaching centres have seriously unbalanced an already highly unrepresentative case mix. The gradual loss of general physicians and surgeons from the staffs of teaching hospitals means that the teaching that students receive has become both more specialised ' and more subject to chance. Specialists' interests bias the cases referred to them, which inevitably biases the teaching given to students attached to their firms. Luck usually plays a larger part in what students learn than does curricular planning. Other educational threats come from the near certainty that time and enthusiasm for teaching will be squeezed both by the service consequences of Achieving a Balance ${ }^{2}$ and the absolute necessity for academic departments to boost their income from grants and their output of research. Finally, at a practical level, every pressure for shorter hospital stays and more intensive investigation, day care surgery, and community care reduces the opportunity for students to study illness by the patient's hospital bed.

At the same time the financial outlook is very uncertain. The future of the service increment for teaching and research still worries deans. The Department of Health's call for action to unravel the longstanding "knock for knock" arrangements between universities and health authorities may have become temporarily less insistent, but in the NHS of the 1990s managers are not going to be content to allow specialists to devote time to teaching without this time being somehow quantified and paid for. Even less can be expected if teaching hospitals opt for independent trust status.

What is the alternative to simply gritting our teeth and making the most of whatever resources are available? It is crucial to remember that we are considering basic medical education - that which all medical graduates should experience before choosing and training for a specialty. Although it cannot be deep, it should be broad. It must not only introduce students to the specialties but also to medicine in all its guises, ensuring that students recognise that attitudes and skills, as well as knowledge, are essential to the education of an effective doctor.

The assumption of the past 200 years has been that only in hospitals does the requisite combination of teaching skills and patient morbidity come together. There are strong arguments, however, based on the intensity, breadth, and continuity of contact with patients, that generalists could play a much larger part than they do now. ${ }^{3}$ Patients need not be lost to the medical education system just because they are outside the hospital: simultaneous education in primary and secondary care should be our aim. Students, by being physically based in general practices for part of their time, could follow the progress of illness from the first report of symptoms through hospital care to resolution. Their education would be richer as a result. There are huge resources for teaching in the community if we can only find ways of tapping them. Developments are needed on several fronts. Hospital teachers and academic departments of general practice should get together to discuss the threats to education and what they could do about them. We need a group of GP teachers for whom undergraduate education is the main professional activity. We need to know more about the morbidity-and therefore teaching potential - of defined practice populations - and the acceptability to patients, students, and GP teachers of placing students in practices. The problems of medical education will not go away. Together, teachers in hospitals and general practice can overcome them.

NIGEL OSWALD

Director of Studies in General Practice,

University of Cambridge, School of Clinical Medicine,

Addenbrooke's Hospital

Cambridge CB2 2QQ

1 Ball P. Resources and standards in medical education. London: King's Fund Institute, 1989.

2 UK Health Departments, the Joint Consultants Committee, and Chairmen of Regional Health

Authorities. Hospital medical staffing - achieving a balance. London: HMSO, 1987.

3 Oswald N. Why not base clinical education in general practice? Lancet 1989;ii:148-9.

\section{Managing violence in psychiatric hospitals}

\author{
Empathy before drugs
}

Probably one in 10 psychiatric patients assaults staff, although this may be an underestimate. ${ }^{12}$ In psychiatric wards the typical patient who assaults staff is a young psychotic man who tends to remain in hospital longer than his non-violent counterpart. He is more likely to be held formally and to have a history of violence and previous admissions. ${ }^{3+}$ Such patients may suffer from schizophrenia, substance misuse, or an organic brain syndrome. Hostility and poor control of impulses are the most consistent predictors of assault, although accurate prediction is possible in no more than a third of cases. ${ }^{5}$ Very anxious, aroused, or paranoid patients are the most likely to express themselves in physical violence. Alcohol, stimulant drugs, and benzodiazepines contribute to disinhibition and the subsequent threat of violence. Warning signs are usually present: they include rapid breathing, clenched fists, loud talking or chanting, restless or repetitive movements, violent gestures, pacing, and gesticulating. ${ }^{6}$

Forensic units have the most disturbed patients but few assaults, reflecting high staffing ratios. Violence, when it does occur, is usually more serious and results in greater injury. In 